\title{
Characteristics of Sagittal Spino-Pelvic Alignment in Japanese Young Adults
}

\author{
Kenji Endo, Hidekazu Suzuki, Hirosuke Nishimura, Hidetoshi Tanaka, \\ Takaaki Shishido, Kengo Yamamoto \\ Department of Orthopedic Surgery, Tokyo Medical University, Tokyo, Japan
}

\begin{abstract}
Study Design: Radiological analysis of normal patterns of sagittal alignment of the spine.
Purpose: This study aimed to clarify the characteristics of normal sagittal spino-pelvic alignment in Asian people.

Overview of Literature: It is known that there are differences in these parameters based on age, gender, and race. In order to properly plan for surgical correction of the spine for Asian patients, it is necessary to understand the normal spino-pelvic alignment parameters for this population.

Methods: This study analyzed 86 Japanese healthy young adult volunteers (48 men and 38 women; age 35.9 \pm 11.1 (mean \pm standard deviation [SD]). The following parameters were measured on lateral standing radiographs of the entire spine: sagittal vertical axis (SVA), horizontal distance between the C7 plumb line and the posterior superior corner of the superior margin of S1, thoracic kyphotic angle (TK), lumbar lordotic angle (LLA), sacral slope (SS), pelvic tilt (PT), and pelvic incidence (PI).

Results: The values (mean \pm SD) of SVA, TK, LLA, SS, PT, and PI were $8.45 \pm 25.7 \mathrm{~mm}, 27.5 \pm 9.6^{\circ}, 43.4 \pm 14.6^{\circ}, 34.6 \pm 7.8^{\circ}, 13.2 \pm 8.2^{\circ}$, and $46.7 \pm 8.9^{\circ}$, respectively. The Japanese young adults evaluated in this study tended to have a smaller PI, LLA, TK, and SVA than most Caucasian people. Regarding gender differences, SVA was significantly longer and TK was significantly smaller in men; however, there was no statistically significant difference in LLA, SS, PA, and PI.

Conclusions: Japanese young adults apparently have smaller PI and LLA values than Caucasian people. When making decisions for optimal sagittal spinal alignment, racial differences should be considered.
\end{abstract}

Keywords: Sagittal alignment; Normal patterns; Adult spine

\section{Introduction}

Proper total spinal sagittal alignment is important to not only maintain balanced standing posture, but also reduce the pain component of quality of life (QOL). Iatrogenic mal-alignment after spinal instrumentation surgery, known as "flat back syndrome," is a reported cause of persistent low-back pain. For surgical planning of spinal realignment, it has recently become possible to evaluate the optimal spinal sagittal alignment using the spinal parameters of a target Caucasian population [1]. However, there are noted postural differences among the human races [2-4]. Knowledge of the standard sagittal spinal parameters of Japanese people is important; nevertheless, studies of sagittal spino-pelvic parameters in the Japanese population are apparently few and the methods of obtaining these parameters are varied [2]. This study involved young adult Japanese and followed the recent research

Received Oct 11, 2013; Revised Nov 1, 2013; Accepted Nov 5, 2013

Corresponding author: Kenji Endo

Department of Orthopedic Surgery, Tokyo Medical University, 6-7-1 Nishishinjuku, Shinjuku-ku, Tokyo 160-0023, Japan

Tel: +81-(3)-3342-6111, Fax: +81-(3)-3342-5295, E-mail: kendo@tokyo-med.ac.jp 
Table 1. Mat erials and parameters

\begin{tabular}{lccccc} 
Parameters & Mean & Range & Standard deviation & Standard error & $\begin{array}{c}95 \% \text { Confidence } \\
\text { interval }\end{array}$ \\
\hline Age $(\mathrm{yr})$ & 35.9 & 23 to 59 & 11.1 & 1.6 & 29.6 to 43.9 \\
\hline Body mass index $\left(\mathrm{kg} / \mathrm{m}^{2}\right)$ & 21.4 & 16.2 to 27.5 & 2.8 & 0.4 & 20.6 to 22.3 \\
\hline Sagittal vertical axis & 8.45 & -40 to 67 & 25.7 & 1.3 & 2.9 to 14.0 \\
\hline Thoracic kyphotic & 27.5 & 9 to 46 & 9.6 & 1.6 & 24.9 to 30.1 \\
\hline Lumbar lordotic angle & 43.4 & 8 to 68 & 8 to 70 & 7.80 .8 & 40.3 to 46.6 \\
\hline Sacral slope & 34.6 & -13 to 46 & 8.2 & 0.89 & 26.2 to 32.9 \\
\hline Pelvic tilt & 13.2 & 33 to 72 & 8.9 & 0.96 & 11.4 to 14.9 \\
\hline Pelvic incidence & 46.7 & & 44.8 to 48.6 \\
\hline
\end{tabular}

spinal parameters of the Scoliosis Research Society $[1,5]$.

\section{Materials and Methods}

This study included 86 adult Japanese volunteers (48 men and 38 women), aged from 23 to 59 years ( $35.9 \pm 11.1$; mean \pm standard deviation $[S D]$ ), who had no back pain at the time of the study or had never sought medical advice for back pain (Table 1). Those enrolled had no hip or knee joint deformities. The subjects were mainly doctors, nurses, and other allied health professionals affiliated with the medical university hospital where the study was conducted. All subjects provided written informed consent after explanation of the experimental protocol, and this study was approved by the Institutional Review Board of our institution.

All subjects underwent frontal and lateral radiography of the entire lumbo-sacral spine and the hip joints, in both standing positions with their hands gently clasped in front of their trunks, which is functionally representative of relaxed standing posture [6]. Lateral radiographs of the lumbar spine were obtained on a vertical film $(30 \times 90$ $\mathrm{cm}$ ) maintaining a constant distance between the subject and the radiographic source. On marked X-ray films, the following radiographic parameters were measured by computer analysis as described previously [6]: 1) sagittal vertical axis (SVA), defined as the horizontal distance between the $\mathrm{C} 7$ plumb line and the posterior superior corner of the superior margin of S1;2) thoracic kyphotic angle (TK), the angle between the cranial endplate of $\mathrm{T} 4$ and the caudal endplate of T12;3) lumbar lordotic angle (LLA), the angle from the upper endplate of L1 to the upper end plate of S1;4) sacral slope (SS), the angle between the superior endplate of S1 and a horizontal axis; 5) pelvic tilt (PT), the angle between the line connecting the midpoint of the sacral plate to the axis of the femoral heads and the vertical axis; and 6) pelvic incidence (PI), the angle between the perpendicular to the sacral plate at its midpoint and the line connecting the point to the middle axis of the femoral heads (Fig. 1). The radiographs were measured twice by the first observer (K.E., a boardcertified orthopedic spinal surgeon), then independently measured on different days by a second observer (H.S., also a board-certified orthopedic spinal surgeon). Descriptions of this method's accuracy, including the intraand inter-observer agreements, were described in detail in a previous paper [6].

A professional medical statistical consultant performed the statistical analyses using the JMP software package, ver. 8.0 (SAS Institute Inc., Cary, NC, USA). An unpaired $t$-test was used to analyze the differences in the spinal and pelvic parameters between men and women. The correlations between the variables of spino-pelvic parameters were examined using the Spearman's rank correlation coefficient. $p$-values of less than 0.05 were considered to indicate a statistically significant difference.

\section{Results}

The mean values of SVA, TK, LLA, SS, PT, and PI were $8.45 \pm 25.7 \mathrm{~mm}, 27.5 \pm 9.6^{\circ}, 43.4 \pm 14.6^{\circ}, 34.6 \pm 7.8^{\circ}$, $13.2 \pm 8.2^{\circ}$, and $46.7 \pm 8.9^{\circ}$ (mean $\pm S D$ ), respectively (Table $1)$. The correlation coefficients between PI and PT, SS, LLA were $r=0.39(p=0.001), r=0.60(p<0.001), r=0.36$ 
Table 2. Correlation matrix among the spinal and pelvic parameters

\begin{tabular}{|c|c|c|c|c|c|c|}
\hline Parameters & SVA & $\mathrm{TK}$ & LLA & SS & PT & $\mathrm{Pl}$ \\
\hline SVA & 1 & - & - & - & - & - \\
\hline TK & $\begin{array}{l}0.15 \\
0.80\end{array}$ & 1 & - & - & - & - \\
\hline LLA & $\begin{array}{l}-0.33 \\
0.0004\end{array}$ & $\begin{array}{l}0.14 \\
0.11\end{array}$ & 1 & - & - & - \\
\hline SS & $\begin{array}{l}0.07 \\
0.30\end{array}$ & $\begin{array}{r}-0.14 \\
0.87\end{array}$ & $\begin{array}{c}0.44 \\
<0.001\end{array}$ & 1 & - & - \\
\hline PT & $\begin{array}{l}0.04 \\
0.40\end{array}$ & $\begin{array}{r}-0.09 \\
0.32\end{array}$ & $\begin{array}{l}-0.30 \\
0.008\end{array}$ & $\begin{array}{r}-0.15 \\
0.08\end{array}$ & 1 & - \\
\hline $\mathrm{PI}$ & $\begin{array}{l}0.06 \\
0.25\end{array}$ & $\begin{array}{r}-0.08 \\
0.43\end{array}$ & $\begin{array}{l}0.36 \\
0.001\end{array}$ & $\begin{array}{c}0.60 \\
<0.001\end{array}$ & $\begin{array}{l}0.39 \\
0.001\end{array}$ & 1 \\
\hline
\end{tabular}

Upper line, correlation coefficient; lower line, $p$-values.

SVA, sagittal vertical axis; TK, thoracic kyphosis; LLA, lumbar lordotic angle; SS, sacral slope; PT, pelvic tilt; PI, pelvic incidence.

( $p=0.001$ ), respectively (Table 2 ). LLA is closely related to the orientation of the pelvis, expressed by the SS, which is in turn affected by the PI. There is interdependence among the pelvic and spinal parameters PI, SS, and LLA.
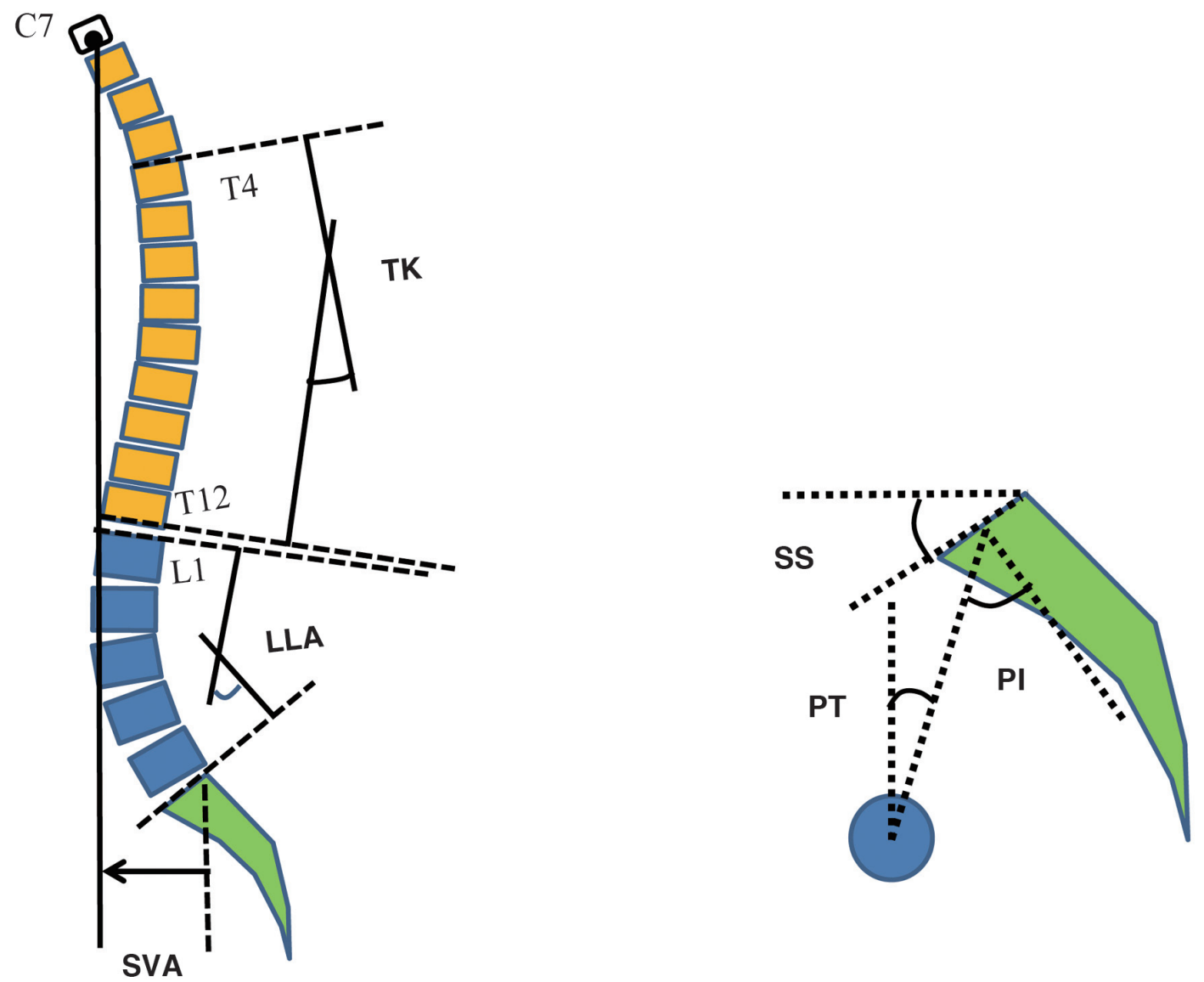

Fig. 1. Measurements of sagittal spinal alignment. TK, thoracic kyphosis; LLA, lumbar lordotic angle; SVA, sagittal vertical axis; SS, sacral slope; PT, pelvic tilt; PI, pelvic incidence. 
Table 3. General and spino-pelvic parameters according to gender group

\begin{tabular}{lccc} 
Parameters & Male subjects & Female subjects & $p$-value \\
Number & 48 & 38 & $<0.01$ \\
Age $(\mathrm{yr})$ & $32.2 \pm 7.8$ & $30.8 \pm 6.6$ & $<0.01$ \\
\hline Height $(\mathrm{cm})$ & $173.6 \pm 5.6$ & $158.7 \pm 5.5$ & $<0.01$ \\
Weight $(\mathrm{kg})$ & $69.4 \pm 9.7$ & $50.4 \pm 15.9$ & $<0.01$ \\
Body mass index $\left(\mathrm{kg} / \mathrm{m}^{2}\right)$ & $23.0 \pm 3.2$ & $30.8 \pm 6.6$ & - \\
SVA & $14.3 \pm 25.1$ & $2.6 \pm 25.6$ & $<0.05$ \\
TK & $24.0 \pm 10.4$ & $30.1 \pm 8.4$ & $<0.05$ \\
LLA & $36.0 \pm 25.2$ & $36.3 \pm 15.2$ & 0.52 \\
SS & $34.8 \pm 7.7$ & $33.8 \pm 8.0$ & 0.55 \\
PT & $12.6 \pm 8.9$ & $14.1 \pm 7.2$ & 0.37 \\
PI & $46.2 \pm 8.2$ & $47.6 \pm 9.7$ & 0.49
\end{tabular}

Values are presented as mean \pm standard deviation.

SVA, sagittal vertical axis; TK, thoracic kyphosis; LLA, lumbar lordotic angle; SS, sacral slope; PT, pelvic tilt; PI, pelvic incidence.

alThe differences between the female and male subjects were compared using the unpaired $t$-test.

The correlations noted here were similar to those of previous reports for Caucasian subjects [7-9].

Regarding gender differences, SVA was significantly longer and TK was smaller in male subjects; however, there were no statistically significant differences in LLA, SS, PT, and PI (Table 3).

\section{Discussion}

The understanding of spinal sagittal alignment for the treatment of spinal disorders is very important. Failure to recognize malalignment in this plane can lead to spinal deformity and reduced QOL [1]. It is reported that abnormal sagittal spinal alignment is affected by aging [10], spinal degeneration [11-13], and hip joint disease [14,15].

Offierski and MacNab [14] described a causal link between arthritis of the hip joint and lumbar spondylosis, naming the constellation of hip, low back pain, and sciatica as the "hip-spine syndrome". Recently, it has become clear that in order to analyze sagittal spinal alignments, the pelvic alignment should be included because of the large effects of individual pelvic morphologies [16].

Legaye et al. [17] reported that the PI is the major pelvic morphologic angle. PI is a fundamental pelvic anatomical parameter that is specific and constant for each individual and determines pelvic orientation. Schwab et al. [1] showed PI to be an important parameter for evaluating the optimal spinal alignment after sagittal spinal realignment surgery. However, there may be possible variations in spinal sagittal posture based on age, gender, and race differences [2].

This study found a sample of Japanese young adults evaluated in this study had a smaller PI. Anatomical differences in the pelvis result in individual characteristics of spino-pelvic alignment. A geometric construction by complementary angles reveals that the anatomical parameter 'PI' can be expressed as the algebraic relation $\mathrm{PI}=\mathrm{SS}+\mathrm{PT}[16]$. This study also found that the Japanese young adults evaluated had a tendency to have a smaller LLA and SS, which was similar to the descriptions from Korean reports (Table 4).

PI had positive correlations with LLA. These results indicate that, because the Japanese young adults evaluated in this study tend to have smaller PI values than most Caucasian people do, the optimal LLA values in Japanese adults should be smaller than those in Caucasian people.

Our results showed that PI had correlations with both SS and LLA, and also affects LLA. PI correlations have shown that the relationship of the spinal anatomical portion is interdependent on its adjacent structures, particularly at the lumbo-pelvic level. However, PI had less effect on SVA; this is because the spinal alignment, including the thoraco-lumbar region, can compensate for the pelvic shape in order to maintain a smaller SVA. This study noted that SVA had a large variation, in agreement with previous reports. Because of spinal compensatory mecha- 
Table 4. Previous reports of spino-pelvic parameters

\begin{tabular}{|c|c|c|c|c|c|c|c|c|}
\hline \multirow[b]{2}{*}{ Parameters } & \multicolumn{4}{|c|}{ Asian } & \multicolumn{4}{|c|}{ Caucasian } \\
\hline & $\begin{array}{c}\text { Kanemura } \\
{[2]}\end{array}$ & $\begin{array}{l}\text { Lee et al. } \\
\quad[4]\end{array}$ & $\begin{array}{c}\text { Kim et al. } \\
{[3]}\end{array}$ & Current & $\begin{array}{l}\text { Schwab } \\
\text { et al. [1] }\end{array}$ & $\begin{array}{c}\text { Roussouly } \\
\text { et al. [19] }\end{array}$ & $\begin{array}{l}\text { Vialle } \\
\text { et al. [8] }\end{array}$ & $\begin{array}{l}\text { Legaye } \\
\text { et al. [17] }\end{array}$ \\
\hline No. subjects & 425 & 80 & - & 86 & 75 & 153 & 300 & 49 \\
\hline Age (yr) & $43.8 \pm 13.9$ & - & - & $35.9 \pm 11.1$ & - & - & - & - \\
\hline SVA (mm) & $6 \pm 26$ & - & - & $8.5 \pm 25.7$ & $20 \pm 30$ & $35.2 \pm 19.4$ & - & - \\
\hline TK (T4-L1) (º) & - & - & - & $27.5 \pm 9.6$ & $41 \pm 12$ & $46.3 \pm 9.5$ & $40.6 \pm 10.0$ & $43.0 \pm 13.0$ \\
\hline LLA (L1S1) ( $\left.{ }^{\circ}\right)$ & $53.6 \pm 9.9$ & 49.4 & 47.0 & $43.4 \pm 14.6$ & $60 \pm 12$ & $61.2 \pm 9.4$ & $60.2 \pm 10.3$ & $60.0 \pm 10.6$ \\
\hline $\operatorname{SS}\left({ }^{\circ}\right)$ & $35.3 \pm 6.4$ & $36.3 \pm 7.8$ & 32.0 & $34.6 \pm 7.8$ & $30 \pm 9$ & $39.6 \pm 7.6$ & $41.2 \pm 8.4$ & $40.0 \pm 8.5$ \\
\hline PT $\left({ }^{\circ}\right)$ & $10.8 \pm 5.5$ & $11.5 \pm 5.3$ & - & $13.2 \pm 8.2$ & $15 \pm 7$ & $11.1 \pm 5.9$ & $13.2 \pm 6.1$ & $11.0 \pm 5.5$ \\
\hline $\mathrm{PI}\left({ }^{\circ}\right)$ & $46.7 \pm 8.7$ & $47.8 \pm 9.3$ & 46.0 & $46.7 \pm 8.9$ & $52 \pm 9$ & $50.6 \pm 10.2$ & $54.7 \pm 10.6$ & $50.2 \pm 10.0$ \\
\hline
\end{tabular}

SVA, sagittal vertical axis; TK, thoracic kyphosis; LLA, lumbar lordotic angle; SS, sacral slope; PT, pelvic tilt; PI, pelvic incidence.

nisms, normal young subjects do not develop abnormal SVA values $(>50 \mathrm{~mm})$ (Table 1$)$. These results were similar to those of previous studies measuring different races (Table 4) [2-4,13,17-19].

However, because of aging or overload to the spine, the resultant loss of spinal compensatory function would lead to a pathological spinal deformity.

There have been various reports regarding gender differences. It has been reported that the female lumbar and sacral geometry (PI, LLA, and SS) is considerably different from the male lumbar and sacral geometry $[13,17,20]$. Other reports showed that lumbar lordosis, as well as thoracic kyphosis, was independent of gender [21,22]. Our results did not reveal any gender differences in pelvic morphologic angle or lumbar and pelvic alignment. As there are gender differences in pelvic shape, there may also be gender differences in sagittal spinal alignment. However, in the Japanese young adults evaluated in this study, the individual variations in lumbar sagittal and pelvic alignment are larger than the gender differences.

This study had some limitations. The number of subjects was relatively small. Thus, we could not extrapolate our results to be representative of Japanese standard values; however, the characteristics are not contradictory to the previous data [2-4]. It is suspected that other Mongoloid populations may have similar sagittal spinal alignments. Despite these limitations, we consider that the current results could contribute to not only the understanding of normal sagittal spinal alignment, but also serve as a basis for realignment strategies in Japa- nese young adults. In future studies, a larger sample that includes a more representative sample of the general population of Japanese people with a wider variation in socio-demographic variables should be evaluated. The outcomes of surgical realignment surgery should also be evaluated for Japanese patients.

\section{Conclusions}

Japanese young adults apparently have smaller PI and LLA values than Caucasian people. When making decisions for optimal sagittal spinal alignment, racial differences should be considered.

\section{Conflict of Interest}

No potential conflict of interest relevant to this article was reported.

\section{Acknowledgments}

We are indebted to Dr. Clifford A. Kolba (Ed. D., D.O. M.P.H.), and Associate Professor Edward F. Barroga (D.V.M., Ph.D.) of the Department of International Medical Communications of Tokyo Medical University for their editorial review of the English manuscript.

\section{References}

1. Schwab F, Patel A, Ungar B, Farcy JP, Lafage V. Adult 
spinal deformity-postoperative standing imbalance: how much can you tolerate? An overview of key parameters in assessing alignment and planning corrective surgery. Spine (Phila Pa 1976) 2010;35:2224-31.

2. Kanemura T. Sagital spino-pelvic alignment in an asymptomatic Japanese population. J Spine Res 2011;2: 52-8.

3. Kim WJ, Kang JW, Yeom JS, et al. A comparative analysis of sagittal spinal balance in 100 asymptomatic young and older aged volunteers. J Korean Soc Spine Surg 2003;10:327-34.

4. Lee CS, Chung SS, Kang KC, Park SJ, Shin SK. Normal patterns of sagittal alignment of the spine in young adults radiological analysis in a Korean population. Spine (Phila Pa 1976) 2011;36:E1648-54.

5. Schwab F, Ungar B, Blondel B, et al. Scoliosis Research Society-Schwab adult spinal deformity classification: a validation study. Spine (Phila Pa 1976) 2012;37:1077-82.

6. Suzuki H, Endo K, Mizuochi J, Kobayashi H, Tanaka $\mathrm{H}$, Yamamoto K. Clasped position for measurement of sagittal spinal alignment. Eur Spine J 2010;19:782-6.

7. Jackson RP, Peterson MD, McManus AC, Hales C. Compensatory spinopelvic balance over the hip axis and better reliability in measuring lordosis to the pelvic radius on standing lateral radiographs of adult volunteers and patients. Spine (Phila Pa 1976) 1998; 23:1750-67.

8. Vialle R, Levassor N, Rillardon L, Templier A, Skalli W, Guigui P. Radiographic analysis of the sagittal alignment and balance of the spine in asymptomatic subjects. J Bone Joint Surg Am 2005;87:260-7.

9. Berthonnaud E, Dimnet J, Roussouly P, Labelle H. Analysis of the sagittal balance of the spine and pelvis using shape and orientation parameters. J Spinal Disord Tech 2005;18:40-7.

10. Takemitsu Y, Harada Y, Iwahara T, Miyamoto M, Miyatake Y. Lumbar degenerative kyphosis. Clinical, radiological and epidemiological studies. Spine (Phila Pa 1976) 1988;13:1317-26.

11. Barrey C, Jund J, Noseda O, Roussouly P. Sagittal balance of the pelvis-spine complex and lumbar degen- erative diseases. A comparative study about 85 cases. Eur Spine J 2007;16:1459-67.

12. Endo K, Suzuki H, Tanaka H, Kang Y, Yamamoto K. Sagittal spinal alignment in patients with lumbar disc herniation. Eur Spine J 2010;19:435-8.

13. Vialle R, Ilharreborde B, Dauzac C, Lenoir T, Rillardon $\mathrm{L}$, Guigui P. Is there a sagittal imbalance of the spine in isthmic spondylolisthesis? A correlation study. Eur Spine J 2007;16:1641-9.

14. Offierski CM, MacNab I. Hip-spine syndrome. Spine (Phila Pa 1976) 1983;8:316-21.

15. Yoshimoto H, Sato S, Masuda T, et al. Spinopelvic alignment in patients with osteoarthrosis of the hip: a radiographic comparison to patients with low back pain. Spine (Phila Pa 1976) 2005;30:1650-7.

16. Roussouly P, Nnadi C. Sagittal plane deformity: an overview of interpretation and management. Eur Spine J 2010;19:1824-36.

17. Legaye J, Duval-Beaupere G, Hecquet J, Marty C. Pelvic incidence: a fundamental pelvic parameter for three-dimensional regulation of spinal sagittal curves. Eur Spine J 1998;7:99-103.

18. Schwab F, Lafage V, Boyce R, Skalli W, Farcy JP. Gravity line analysis in adult volunteers: age-related correlation with spinal parameters, pelvic parameters, and foot position. Spine (Phila Pa 1976) 2006;31:E959-67.

19. Roussouly P, Gollogly S, Berthonnaud E, Dimnet J. Classification of the normal variation in the sagittal alignment of the human lumbar spine and pelvis in the standing position. Spine (Phila Pa 1976) 2005;30: 346-53.

20. Gelb DE, Lenke LG, Bridwell KH, Blanke K, McEnery KW. An analysis of sagittal spinal alignment in 100 asymptomatic middle and older aged volunteers. Spine (Phila Pa 1976) 1995;20:1351-8.

21. Jackson RP, McManus AC. Radiographic analysis of sagittal plane alignment and balance in standing volunteers and patients with low back pain matched for age, sex, and size. A prospective controlled clinical study. Spine (Phila Pa 1976) 1994;19:1611-8.

22. Voutsinas SA, MacEwen GD. Sagittal profiles of the spine. Clin Orthop Relat Res 1986;(210):235-42. 